\title{
Developing new teacher inquiry and criticality: the role of online discussions
}

Adam Unwin

Adam Unwin is a Senior Lecturer in Education at the Institute of Education, University of London, UK. $\mathrm{He}$ is a teacher educator working on Initial teacher Education and Masters courses. Address for contact: 20 Bedford Way, London WC1H 0AL, email: a.unwin@ioe.ac.uk

\begin{abstract}
This work concerns the professional development of UK teachers in their first year of teaching. It is interested in how the online discussions these teachers undertook as part of the Master of Teaching (MTeach) contributed to this development process. The teachers worked in online tutor groups made up of teachers from different schools, phases (primary and secondary) and subjects. The data used was, their accounts of participating in the online discussions written towards the end of this first year of teaching and interviews with a selection of these teachers at a later stage in their career. It appeared that the learning gains of the ODs were enabled and fostered by writing for an audience of peers about their professional practice. These new teachers developed an inquiry centred collegiality, reflexivity and a critical engagement with wider and longer term educational perspectives. The research establishes that the gains from the online discussions were the result of careful pedagogic design at many levels. By foregrounding the situated experiences and interests of the teachers it allowed a 'way in' for them to start to understand the complexities, dilemmas and strategies within their own and others professional practice.
\end{abstract}

\section{Introduction}

This paper analyses and discusses how 'online discussions' (ODs) have contributed the professional learning of a group of new teachers in the UK. These teachers studied the Master of Teaching (MTeach) at the Institute of Education (IOE) University of London while in their first year of teaching.

Central to this research is an exploration of the importance of context, practice and pedagogic design in enabling the development of critical inquiry. Context in this case concerns the professional situation of the teachers (i.e. their schools) and the MTeach course itself. Practice concerns the participants' teaching and how their professional practice could be a key driver to their and others learning. Pedagogic design is interested in how the design that underpinned the ODs prompted teacher inquiry and enabled a deeper learning and criticality about their professional contexts. 
This work acknowledges the potential of learning analytics (LA) defined by the $1^{\text {st }}$ International Conference on Learning Analytics and Knowledge as the 'measurement, collection analysis and reporting of data about learners and their contexts, for the purpose of understanding and optimising learning and the environments in which it occurs'(2011). The work is interested and aligned with aspects of the concept of social learning analytics (SLA) as proposed and discussed by Buckingham Shum and Ferguson (2012). The importance of understanding 'the elements of learning that are relevant when learning in a participatory online culture' (Buckingham Shum and Ferguson, 2012, p. 5) is key to this work. At the same time, this research is cautious about making any definitive claims about what learning is taking place solely by analysis of online contributions.

The paper is organised by providing an overview of the MTeach to explain how the ODs work. There is a section that summarises the main models and thinking about teacher learning and development that underpin the research. This is followed by a brief outline of the research process and a presentation and discussion of the key findings.

\section{The MTeach and online discussion (OD)}

The MTeach course was designed in 2000 to focus on the development of teachers in the challenging early phase of their teaching careers (Daly, Pachler and Lambert, 2004). The DfES recognised that this new course aimed to provide a framework of 'support for talented new teachers in urban schools' (DfES, 2001) encouraging high level professional learning to take place, nurturing an enquiry approach to 'understanding teaching' and raising levels of 'research literacy'.

There are three key themes that illustrate the thinking behind what the course is trying to achieve and the way it operates. First, there is a clear focus on the participants' own teaching, their students, their classrooms and their schools. It is a starting point for them to engage critically with practical and theoretical educational issues by trying to make sense of their situated practice (Lave and Wenger, 1991). Secondly, it is about participants communicating and reflecting on their own and each other's practice. It is believed that this sharing and explaining of their experiences and ideas will not only deepen understanding of the complexities at play in teaching but also encourage reflexivity and analysis. What is important is that this communication fosters the development of a 'community of inquiry' (Garrison and Anderson, 2003; Garrison, Anderson and Archer, 2001) within the online groups.

...a community where individual experiences and ideas are recognised and discussed in light of societal knowledge, norms and values.

(Garrison and Anderson, 2003, p. 4)

This links to the third theme that concerns the development of a deeper understanding of the role of research in education. This is not only about exposure to 
wider debates about teaching and learning than they might experience in their schools, it is also about them critically evaluating or 'researching' what is happening in their own classrooms.

The course is 'mixed mode' in the sense that both face to face (f2f) sessions and online components are used. MTeach course participants are arranged in tutor groups working with these peers both at f2f sessions and while taking part in the ODs.

This research concerns participants who had just completed their initial teacher education (ITE) and were now in their first year of being a teacher. The core module taken in this year is called Understanding Teaching (UT). Table 1 below illustrates the typical interplay of $\mathrm{f} 2 \mathrm{f}$ sessions and ODs in this module.

\begin{tabular}{|c|c|c|c|}
\hline Timing & ODs & 'Understanding Teaching' (UT) Module Activity & Mode \\
\hline September & & Inaugural evening at loE & f2f \\
\hline October & 1 & Starter task & online \\
\hline \multicolumn{4}{|c|}{ Autumn half term } \\
\hline November & & Saturday at loE & $\mathrm{f} 2 \mathrm{f}$ \\
\hline Nov/Dec & 2 & Classroom interactions & online \\
\hline \multicolumn{4}{|c|}{ Christmas holidays } \\
\hline Jan/Feb & 3 & Learning, progression and achievement & online \\
\hline \multicolumn{4}{|c|}{ Spring half term } \\
\hline February & & Saturday at loE & $\mathrm{f2f}$ \\
\hline March & 4 & Evaluating teaching & online \\
\hline \multicolumn{4}{|c|}{ Easter holidays } \\
\hline April/May & 5 & Developing pedagogy & online \\
\hline \multicolumn{4}{|c|}{ Summer half term } \\
\hline June & & $\begin{array}{l}\text { Saturday at loE: Coursework in progress } \\
\text { presentations }\end{array}$ & $f 2 f$ \\
\hline July/August & & Coursework write up & email// \\
\hline
\end{tabular}

\section{Table 1: Structure of UT module}

The UT module runs over the whole academic year. The rationale was that new teachers have substantial workload pressures on them; the module thus needs to be designed to be manageable as well as meaningful and relevant to their early teaching experiences. The ODs follow a broadly common format with: a tutor written briefing paper that introduces the area of focus; a task which outlines the options for them (all require them to look at what is happening in their classroom); two or more digitised readings and some examples of previous participants' postings. Participants are encouraged to read the briefing paper before they choose the task and to engage with the digitised readings before composing their initial posting (usually 300-500 words). They then need to respond to what at least one of the other participants has outlined in their posting. This whole process happens over a $4 / 5$ 
week period with a specific date for completion of the initial posting, then usually the next two weeks allocated for responses.

The ODs ask participants to 'problematise' particular issues (e.g. classroom interactions) in their context of their own classrooms. The fourth OD (Evaluating teaching) builds on the 'problematising' approach in that participants are asked to identify something that interests them in their classroom for the purpose of inquiry. They use a framework for the posting which takes the form of a proposal about what they are interested in and how they want to experiment with and evaluate it. Responses from the group are expected to be both questioning and formative.

The explanation above attempts to clearly locate the research and clarify what an $\mathrm{OD}$ is in the context of this research.

\section{Perceptions of teacher development}

There is a significant body of work concerned with how teachers develop. For the purposes of this paper there is a summary of the three main models of teacher development. These are the competence based or 'standards' approach; the reflective practitioner; and the reflexive teacher. These models are not mutually exclusive and one might find elements of all three in place in a teacher education, training or induction programmes.

Moore in his book 'The Good Teacher' (2004), summarises the model teacher educators will be most familiar with which are the 'standards' used in ITE.

According to this model, teachers are trained in acquisition of certain competences related to aspects of classroom management, long term, medium term and short term planning, developing and sharing subject knowledge, and assessing, recording and reporting students' work- leading to the achievement of prescribed assessable and (presumably) acquired-for-life 'standards'. (Moore, 2004, pp. 3-4)

The arguments for these models tend to be managerial focussing on the requirements (or competences) for teaching effectively (Wilson and Demetriou, 2007).

Competence models do not sit easily with the reflective practitioner approaches which has been adopted widely in ITE (after Schon (1983)). Central to the notion of reflective practice is the focus on the teacher evaluating their own practice in their own particular context rather than the emphasis on particular skills found in competence based models. The idea is that the teacher's own evaluations consider the whole picture as to why issues are occurring within this particular situation and identify context relevant strategies. This process also aims to be part of a cycle of 
continuing development over time rather than a measurement at a moment in time. Reflective practice can even be seen as a counter to competence based approaches (Lucas, 2004), although it is often integrated with standards models.

Moore suggests the co-existence of the competence based and reflective practitioner models has encouraged reflective practice to be inward looking, focused only on the individual and on self improvement. Ward and McCotter (2004, p. 255) warn of reflection being used for 'short-term instrumental value' where for instance teachers are required to record student outcomes. Consequently the benefits of the reflective practitioner model have been narrowed, shifting debate away from the complexities of teaching and the relevance of socio-economic and cultural factors. By becoming individualised and too context specific it can also promote a discourse of blame and feelings of guilt.

Moore argues there is a need to develop reflexivity in teachers. He stresses that reflexive practice goes beyond 'reflection'. Reflexivity requires the critical consideration of wider contexts and histories and an understanding of one's own positioning and behaviour. Moore draws on Boler's concept of a 'pedagogy of discomfort' (1999, p. 176) where teachers' previously learned habits and assumptions (about education) are challenged, enabling them to start to recognize what they do not know. Reflexivity, it is argued, can be facilitated by teacher inquiry. The specific local situation may be a starting point but in itself is not enough. The inquiry needs to include an understanding of the wider issues at play with a critical examination of the teacher's own positioning and influence within and about these contexts. It also needs to be collective in that it is shared, that it opens up rather than closes down discussion.

These differing yet to some extent overlapping views of teacher development provide a way of evaluating and framing what is happening within the ODs and the nature of teacher development that is being facilitated.

\section{Research Design}

The research was interested in the views and experiences of the teachers' participation in the ODs and how this helped them develop. The theoretical perspective adopted for this research was interpretive with a methodological approach that used qualitative data. The research used two sets of data:

1- Written work that a sample of 22 participants completed as part of a different course module during their newly qualified teacher (NQT) year. This written work required participants to critically reflect on how their participation in the ODs has contributed to their professional development.

2- Interviews with 10 of these participants at least 2 years later.

Using this data enabled the research 'to gain access to their accounts and articulations ' (Mason, 1996, pp. 39-40). 
Coding utilised QSR NVivo 8 (NVivo) and analysis was assisted via thick descriptions (Creswell and Miller, 2000). This process used the data to identify codes then themes that helped answer the overall question.

- How have the ODs facilitated new teacher development?

It was also interested in a deeper exploration of what is happening in the ODs and why. Thus the coding looked for data that shed light on the following sub questions.

- What is the nature of new teacher development within this setting?

- What aspects of the ODs do participants see as important in enabling new teacher development?

- How does the pedagogic design of the ODs underpin and enable new teacher development?

The quotes from the teachers used in the findings section below are categorised with different letters for each teacher and 1 and 2 indicating the source of the data explained above.

\section{Findings}

This section of the paper uses examples generated from the research. This is to illustrate how and in what ways the ODs were developing the participants practice and thinking. Headings are used to signal the area and nature of this professional learning.

\section{a. Changing classroom focus}

In the following quote, a teacher ( $\mathrm{T} 1$ ) explains how the ODs changed the way he thinks about his classrooms and students.

The last online discussion improved my understanding of pedagogy and the key factors that should be considered. My focus at the beginning of the year was on what and how I was teaching. I believe my focus has changed during the course of these online discussions. My focus is generally upon the learning taking place rather than my teaching. I have become aware of the different variables as described by Kyriacou. I now consider these variables when planning, teaching and evaluating lessons.

The online community has developed my understanding of the key considerations of effective teaching and learning and has offered different practical strategies to improve my pupils' development as thinkers and learners.

In the year preceding the MTeach participants completed their ITE. ITE requires student teachers to demonstrate evidence of meeting 'standards'. Student teachers may well foreground their performance against the standards rather than focus on 
the learning that is happening in their classes. T1 explains how he feels he has changed from a focus on himself and lesson content to a focus on learning and pupil development. The Kyriacou (2001) reading that T1 refers to proposes a framework of context, process and product variables as one way of deepening understanding about what is happening in the classroom. It is apparent that there is a move in participants' focus from their teaching to student learning and that a wider range of factors are given consideration in their thinking about practice.

\section{b. Sharing Ideas}

The ODs were designed to provide a way of sharing experiences. Y2 explains how the ODs were more than a simple sharing.

... and it wasn't even just people's responses to me that would help. I read X's responses to $Y$, and l'd sit there thinking - oh brilliant. I could use that. Yeah, it was really nice actually. It's a bit like a focus group, you sit and watch everybody interact, and you pick up something from everybody. So yeah, I think people took...it's that same thing, people took care because they knew that we were relying on each other for help. Because it's a real problem and it's real students' lives and real teachers' classroom time, you don't suggest something that's pointless, and if you are going to think about it and suggest something then you try and frame it in a way that makes it easy to use, and helpful.

She explains how being part of a group and reading each other's interactions gave her practical ideas even though these were not specifically addressed to her situation. It is interesting that she points out how her learning and development in this case are not necessarily the result of her contributions or interactions. The idea behind the design of the groups' online activities is that all participants can keep track of what is happening and benefit from this, rather than it being a series of isolated discussions. In part this is the reasoning behind the group size and the focus of each OD. She also rationalises a practical community issue; how participants 'rely' on each other and that because the contexts discussed are real, the suggestions made are carefully thought out and presented. This exemplifies how the use of real contexts is a pedagogic strength of the way the ODs are designed.

\section{c. Questioning}

There is a sense that the ODs encouraged an inquiry approach to what was happening in participants' schools, classrooms and in this case at Local Authority (LA) level about a primary marking policy.

I remember they introduced a new marking policy when I was there, and it was - we have to do this, this, and this. But there was very little why? It was just this is what we expect you to do. Yes, the MTeach was more about why, and the borough was more about how or what? 
E2 felt there was a potential narrowness of just being expected to implement policy without understanding more deeply the purpose behind such changes. Similarly P2 explains how he has developed a critical approach to new initiatives that he feels often simplify what is happening. He was,

...suspicious of any approach which is a technicist approach, so any time I get INSET...we had, last Tuesday, AD brought Geoff Petty in [well known active learning guru/consultant], and all the other teachers were very positive about what he was doing. And while I couldn't disagree with all the pedagogies at the basis of what he was saying, my kind of immediate response to the session was that of a petulant child. You know, I am just not really interested in any of this, the study buddies, whatever. Once you put a label on it you close down an opportunity to enquire into it.

This over simplification annoys P2 because he feels it detracts from what really needs to happen, which is a deeper thinking or 'an opportunity to enquire' about the issue.

\section{d. Writing}

The process of writing was seen as important as it helped them develop a deeper analysis of their classroom practice.

I found taking the time to form my submissions to the online discussions the most beneficial part to my development. Consolidating my thoughts into writing to share with others helped me to analyse my teaching more carefully.

P1 recounts how the combination of other participants' postings, his own experience, his interpretation of literature and the structure of the online group informed and influenced what he gained though writing for the ODs.

... my peers' contributions had become integral to my thinking

He goes on to say

...the accounts of classrooms came to me through my understanding of the literature, grounding the theory in diverse practice. Above all, my peers provided my sense of audience - the form and purpose that enabled me to work things out in writing.

This illustrates how the multi faceted nature of the ODs is used by P1. It is apparent that the learning arises from a mixture of interpersonal and intrapersonal thinking. What he was reading in the ODs was 'integral' to his thinking: he explains how the 
variety of practice allowed him to make more sense of the literature, and he describes it as 'grounding the theory'. This is important as there is a danger that academic and professional readings in isolation might appear too abstract. In this case, because the ODs require a sharing of practical experiences framed by readings, the literature becomes more relevant and accessible.

\section{Summary of findings}

The data presented above are examples to illustrate the nature of the teacher learning the ODs facilitated. It is important to recognise that the learning and development engendered by the ODs such as the processes of reading, thinking and action in their own practice are not overt contributions or actions within the ODs. Therefore we must be cautious by making assumptions about online activity. As Siemens and Long warn 'Learning is messy and using analytics to describe learning won't be easy.' (Siemens and Long, 2011).

The ODs assisted them in developing their day to day (and longer term) practice, a main one being the design and development of teaching and learning strategies with their own students. The writing process made participants think carefully about their contexts and made them analytical about their practice. This learning was a gradual over time as participants used the ODs to look at their classrooms and situated experiences in different ways. Their participation included questioning literature, practice and policy and the adoption of an inquiry approach to situations and issues. This criticality included recognition of the complexity of factors at play in education and the limitations of short term and 'quick fix' solutions or strategies. The inquiry approach encouraged deeper, wider and forward thinking about practice rather than narrow, individualistic reflections about what has happened. These new teachers were starting to make what Moore called the 'reflexive turn' (Moore, 2004, p. 141) becoming 'authentically and constructively critical...challenging rather than confirmatory' (Moore, 2004, p. 142).

What is happening within the ODs is a joint process akin with the concept of a 'community of inquiry' (Garrison and Anderson, 2003; Garrison, Anderson and Archer, 2001) referred to earlier. There is an integration of the cognitive, social and teaching presences proposed in their work. Thus the ODs offer a formative and collaborative knowledge construction process but 'it is the individual learner who must grasp its meaning or offer an improved understanding' (Garrison and Anderson, 2003, p. 13).

\section{Pedagogic design}

The ODs allowed participants to utilise their own and each other's professional teaching experiences as a critical 'way in' to the topics and issues covered by the 
course. It is the course team that designs and sets up the ODs (the timings, structures, requirements and so on) and these are pedagogic decisions. This research has confirmed the importance of not being constrained or pushed in a particular direction by the technologies. Rather, there is a need to develop approaches that utilise the affordances technology offers to achieve the desired pedagogy. Laurillard poses this as a question.

How do we ensure that pedagogy exploits the technology, and not vice versa?

(Laurillard, 2009, p. 6)

This design process requires an understanding of the options and potential of the technology so that the course can use these in a way that contributes to rather than undermines its pedagogic aims.

\section{Conclusion}

There is a documented tendency to assume educational benefits will naturally follow when introducing technology to the learning process. There is a need to take a critical and analytical perspective on why a technological innovation might improve (or not) the learning process (Laurillard, 2002; Mishra and Koehler, 2006; Oliver, 2003). What underpins this work and makes it distinctive is that it foregrounds the importance of pedagogic design. To achieve the development of criticality and teacher inquiry requires careful thinking about what participants are asked to do in the online elements of a course. This design included the use of situated experiences as a central and overarching dimension, the use of models, frameworks, readings and exemplars, having manageable timelines and clear structures, and a shared and formative inquiry element. Thus the design is itself an analytical process that starts with the learner.

Current work from the Open University on learning analytics also foregrounds the importance of the learner 'Their involvement is key to understanding the local context' (Sharples et al., 2013, p. 16). Fisher, Higgins and Loveless (2006) explain how teacher learning is complex, multifaceted and 'resistant to standardisation' (2006, p. 2) but there are 'affordances' (2006, p. 3) digital technologies can offer to enhance teacher learning. They suggest 'clusters of purposeful activities' (2006, p. 20) that can develop the affordances of 'knowledge building', 'distributed cognition', 'community and communication' and 'engagement'. The MTeach course team have designed ODs that exploit these affordances to enable a particular form of teacher learning. They have achieved this by considering learners, the contexts they are working in, the pressures they are under and their learning needs. 
1st International Conference on Learning Analytics and Knowledge (2011, February 27-March 1). 1st International Conference on Learning Analytics and Knowledge Paper presented at the 1st International Conference on Learning Analytics and Knowledge Banff, Alberta.

Boler, M. (1999). Feeling Power: Emotions and Education. New York and London: Routledge.

Buckingham Shum, S. and Ferguson, R. (2012). 'Social Learning Analytics'. Educational Technology \& Society, 15 (3), 3-26.

Creswell, J. and Miller, D. (2000). 'Determining Validity in Qualitative Inquiry Getting Good Qualitative Data to Improve Educational Practice'. Theory into Practice 39 (3), 124-130.

Daly, C., Pachler, N. and Lambert, D. (2004). 'Teacher learning: towards a professional academy'. Teaching in Higher Education, 9 (1).

DfES. (2001). Teachers' standards framework : helping you develop. London: Department for Education and Skills.

Fisher, T., Higgins, C. and Loveless, A. (2006). Teachers learning with Digital Technologies: A review of research and projects: Futurelab.

Garrison, D. and Anderson, T. (2003). E-Learning in the 21st Century: A Framework for Research and Practice. London: RoutledgeFalmer.

Garrison, D., Anderson, T. and Archer, W. (2001). 'Critical thinking, cognitive presence and computer conferencing in distance education'. American Journal of Distance Education, 15 (1), 7-23.

Kyriacou, C. (2001). 'Ways of thinking about effective teaching', Effective Teaching in Schools: Theory and Practice. Cheltenham: Stanley Thornes.

Laurillard, D. (2002). Rethinking university teaching : a conversational framework for the effective use of learning technologies. (2nd ed.). London: Routledge Falmer.

Laurillard, D. (2009). 'The pedagogical challenges to collaborative technologies'. Journal International Journal of Computer-Supported Collaborative Learning 4 (1), 5-20.

Lave, J. and Wenger, E. (1991). Situated Learning: Legitimate Peripheral Participation. Cambridge: Cambridge University Press. .

Lucas, N. (2004). Teaching in Further Education: New perspectives for a changing context. London: Institute of Education, University of London.

Mason, J. (1996). Qualitative Researching London: Sage.

Mishra, P. and Koehler, M. J. (2006). 'Technological Pedagogical Content Knowledge: A Framework for Teacher Knowledge'. Teachers College Record, 108 (6), 1017-1054.

Moore, A. (2004). The Good Teacher: Dominant discourses in teaching and teacher education. London: RoutledgeFalmer.

Oliver, M. (2003). 'Looking Backwards, Looking Forwards: An overview, Some Conclusions and an Agenda'. In J. Seale (Ed.), Learning technology in transition : from individual enthusiasm to institutional implementation (pp. 166). Lisse ; Abingdon: Swets and Zeitlinger.

Schon, D. A. (1983). The Reflective Practitioner. New York: Basic Books.

Sharples, M., McAndrew, P., Weller, M., Ferguson, R., FitzGerald, E., Hirst, T. and Gaved, M. (2013). Innovating Pedagogy 2013: Open University Innovation Report 2. Milton Keynes: The Open University. 
Siemens, G. and Long, P. (2011). 'Penetrating the fog: Analytics in Learning and Education'. EDUCAUSE Review, 46 (5).

Ward, J. and McCotter, S. (2004). 'Reflection as a visible outcome for preservice teachers'. Teaching and teacher education, 20 (3), 243-257.

Wilson, E. and Demetriou, H. (2007). 'New teacher learning: substantive knowledge and contextual factors '. The Curriculum Journal, 18 (3), 213-229. 